\title{
DA LEITURA ÀS AVESSAS AO NARCISO ESTILHAÇADO
}

\author{
Edson Rosa da Silva*
}

Seul [' art vivant] exprime pour les autres et nous fait voir à nous-mêmes notre propre vie, cette vie qui ne peut pas s' "observer", dont les apparences qu'on observe ont besoin dêtre traduites et souvent lues a rebours et péniblement déchifrées. Ce travail qu'avaient fait notre amour-propre, notre passion, notre esprit d'imitation, notre intelligence abstraite, nos habitudes, c'est ce travail que lart defera, c'est la marche en sens contraire, le retour aux profondeurs ou ce qui a existé réellement git inconnu de nous, qu'il nous fera suivre.

MARCEL PROUST

(Le temps retrouvé)

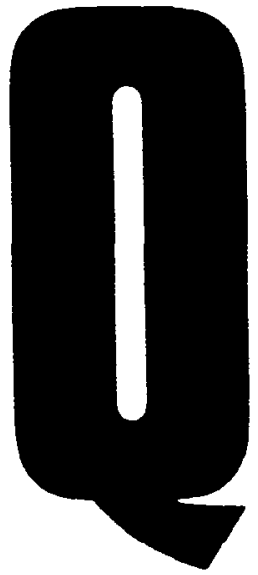

uis começar esta reflexão por Marcel Proust; quero começar esta reflexão por Marcel Proust. Se insisto na diferença temporal, na diferença dos tempos verbais, nảo é por mero efeito retórico. É porque preciso demarcar dois momentos distintos. O primeiro ("quis começar esta reflexão por Marcel Proust") passa pelo passional; o outro ("quero começar esta reflexāo por Marcel Proust'”, posterior à paixāo, passa pelo racional.

Quero, pois, e começo, assim, esta reflexão por Marcel Proust porque acredito que toda reflexão sobre o romance francês do século $\mathrm{XX}$ tem que percorrer os caminhos por ele abertos. Assim como acredito que toda reflexão sobre a renovação da narrativa francesa

* Universidade Federal do Rio de Janeiro 
também passa obrigatoriamente por André Gide. Ambos tratam da busca de uma identidade que, por mais que os críticos a liguem à recuperação de um percurso pessoal, aponta muito mais, e sobretudo, para a própria identidade do romance, para a identidade de uma narrativa que romanceia sua própria escritura.

E a arte desta busca que me parece definir-se na citaçāo de $L e$ temps retrouvé que pus em destaque, esta arte que nos faz ver, nāo as aparências, mas que convida a uma outra leitura, pois "as aparências que observamos precisam ser traduzidas, freqüentemente lidas ds avessas e com dificuldades decifradas". É este ato consciente de uma "leitura às avessas" que vai definir, a meu ver, uma postura cada vez mais característica de uma leitura que não se quer representativa daquilo que se observa, porém auto-representativa daquilo que nela se opera. É o ato da tradução, da decifração, não da realidade, mas, como indica o mesmo texto algumas linhas antes, ato de decifraçāo, "sob a matéria, sob a experiência, sob as palavras, de algo diferente" (Le temps retrouve, p.258), das diferenças que ali se operam e que, em constante diálogo, compōem o texto.

De como a literatura lê o mundo às avessas, talvez seja disso que nos fala a obra de Proust, reinventando e recuperando através da memória involuntária fragmentos de uma experiência, fragamentos que, reordenados pela escritura, tomam-se textos, teia significante, onde interagem os fragmentos da memória, tecido onde se tece a identidade de uma escritura.

Lembro aqui um texto fundamental da obra proustiana - o episódio da "madeleine". Ou melhor, a imagem que vem logo após o desabrochar da memória desperta pelo gosto da "madeleine":

E como naquele jogo japonês de mergulhar numa bacia de porcelana cheia de água pedacinhos de papel, até entâo indistintos e que, depois de molhados, se estiram, se delineiam, se colorem, se diferenciam, tornam-se flores, casas, personagens consistentes e reconhecíveis, assim todas as flores do nosso jardim e as do parque do Sr. Swann, e as ninféias do Vivonne, e a boa gente da aldeia e suas pequenas moradias e a igreja e seus arredores, tudo isso que toma forma e solidez, saiu, cidade e jardins, da minha xícara de chá. ( $D u$ côté de chez Swann, p.58).

Jogo e fragmentos são dois aspectos que a consciência cada 
vez mais aguçada do ato de escrever vai destacar na literatura do século XX. E claro que essa consciência não nasceu neste século. Seria preciso desconhecer Diderot, no século XVIII, e Mallarmé, no século XIX (limito-me a só citar dois nomes) para fazer tal afirmação. $O$ que se pode dizer, no entanto, é que o avesso do bordado, os riscos e borrōes do trabalho do escritor, durante muito tempo e aos olhos de muitos, não faziam parte das "bienséances" literárias.

O meu propósito era começar por Marcel Proust e nāo falar de Proust. De novo fui levado pela paixāo. Pretendia, a partir da busca da identidade da escritura e da identidade na escritura, e do jogo de fragmentos na composição do texto, apontar algumas constantes da literatura contemporânea.

Aqui, cabem igualmente algumas precisōes. Discutir o espaço da produçāo narrativa contemporânea na França é tema para várias teses e não para um simples artigo. Querer englobar e generalizar são atitudes pouco convenientes a quem acredita que a pesquisa é dinâmica e cheia de surpresas. Querer consagrar obras e autores ainda menos aconselhável quando se sabe que só o tempo e o recuo permitem a apreensāo total (ou quase) das diferenças, a contemplaçāo à distância do objeto de estudo.

A pesquisa que venho realizando sobre literatura francesa contemporânea conduziu-me ultimamente à narrativa biográfica e autobiográfica, o que me tem levado a refletir sobre aspectos na minha opiniāo bastante importantes para a teoria e a crítica literárias, como a relação entre a ficção e a realidade, a questão dos gêneros, a alteridade do sujeito e a valorizaçāo do lúdico, entre outros.

Dentre as obras que têm despertado meu interesse, escolhi uma bem recente, publicada em 1988, e traduzida, entre nós, pela Editora Rocco, em 1989, talvez desconhecida de muitos, que se intitula $O s$ últimos dias de Charles Baudelaire, do escritor e filosofo BernardHenri LÉVY. E por quê? A leitura da obra, além de apaixonar-me, fez-me crer que poderia discorrer sobre aqueles aspectos que vêm sendo estudados como característicos de tempos novos (novos que já datam dos anos de 1950) e que se convencionou chamar de pós-modernidade.

Durante dias e dias, convivi com a biografia de Baudelaire via Lévy, deleitei-me com sua originalidade, com seu espírito inventivo, com a análise da obra de Baudelaire que o romance de Lévy parecia camuflar sob a etiqueta de uma biografia.

Li a história do final da vida do poeta francês contada por diversos narradores, através dos mais variados pontos de vista: a Sra. Germaine Lepage, zeladora do Hotel do Grand-Miroir, em Bruxelas, com sua linguagem simplória, familiar, até mesmo errada, por vezes, 
de quem conta e não de quem escreve; o fotógrafo Charles Neyt, com seu relato "realista" dos encontros em casa de Adele Hugo, defensor do amigo poeta pouco considerado e sem reconhecimento pelo círculo pró Victor Hugo; o diário de Jeanne Duval, a amante negra, sensual, infiel porém sedutora, em cujo texto se vêm aninhar fragmentos de versos do poeta contrastando com sua fala habitual e de pouca cultura; a carta do editor de Baudelaire, Auguste PouletMalassis, ao narrador, onde comenta o romance em curso, o procedimento da escritura, o texto que se tece e ao qual a carta se vem trançar, as cartas da Sra. Aupick. māe de Baudelaire, ao narrador, sua tentativa de afastá-lo de seu filho, com seu estilo claro e sua vontade determinada; e o relato do padre Dejoncker, chamado a ministrar o santo viático ao doente maldito, e capaz de compreender (com que avanço no tempo!) que a doutrina do poeta revoltado é a marca de um catolicismo desviado, claro, mas, apesar disso, obsedado pela cruz. Ligando esse conjunto de textos vários, a voz do narrador tece um texto maior, usando assim os documentos inventados do escritor na sua invençảo de narrador: a biografia do poeta. Jogo de armar onde cada fragmento inventado reinventa o todo. Jogo de verdade/mentira, en que o narrador "rouba" a identidade de Baudelaire e, sob a capa do nome civil, recria uma outra personalidade. Coerente, é bem verdade, próxima do Baudelaire-um que conhecemos, perpassada porém pelo Baudelaire-outro do narrador, ou de suas próprias ficçōes, de ficçōes outras, das ficçōes de um outro outro, enfer ou ciel, qu'importe!, personalidade de um outro novo. A carta de Auguste Poulet-Malassis revela a artimanha do narrador, o "delito" cometido, ao mesmo tempo que "garante" a veracidade dos fatos:

Os próprios fatos sāo exatos. Sua cronologia respeitada. Confirmo a crise de Saint-Loup em 15 de março. O trem perdido para Paris em 18. O lanche na casa de Adele Hugo em 21. O jantar na casa de Neyt. A nova crise em 22 . O começo da afasia. A hemiplegia. Todavia, no fundo, quero dizer: sobre o método que consistiria (pois tal é bem sua idéia, não é?) em introduzir -se assim, como que por arrombamento, na cabeça de um poeta que o senhor mal conheceu, depois em fazê-lo falar pela sua boca. com suas patavras e suas preocupaçóes, tolere que eu the manifeste minha extrema perplexidade - acrescida, e e mais grave, das mais expressas reservas quanto à idéia de conjunto que, de passagem, o senhor desenvolve. (LEVY. p.151. grifos meus) 
O narrador prometéico, ladrão da inspiraçāo divina do poeta, ladrāo por arrombamento da biografia baudelairiana, escreve, assim, a partir do que sabe e do que não sabe, e sobretudo, a partir do que pode evocar e sugerir a obra, ou os fatos históricos ou as posiçōes políticas, escreve, portanto, a vida outra de Baudelaire. Nāo pela memória, pelo coração. Não rememora, recorda. Filtra pelo sentimento, pelo sabor da obra, aquilo que os fatos revelam ou calam.

Numa de suas intromissóes (por arrombamento, sempre!) na cabeça do poeta, o narrador pensa com ele, afirma que pensa em outra coisa que não o de hábito:

Está num universo que subitamente não tem mais nada a ver com o de seu quarto, nem da noite que acaba de passar. E tudo se desen rola como se aquela crise, tornando seu corpo pesado, tivesse aliviado o espírito e o tivesse transportado para um mundo diferente, estranho ao que está ali, à sua volta. Ele sente o corpo aqui - a cabeça em outra parte. Tem o corpo em Bruxelas, Hotel do Grand-Miroir - mas a alma está em Paris, 10 anos, 20 anos, 30 ou 40 anos atrás. E aquela alma é un amedrontador e delicioso carrossel que faz com que outros lugares, outros hotéis, outros rostos, outros perfumes, venhum revolver os de hoje, invadi-los, substitui-los. (LEVY, p.84).

A receita está aí: as recordaçōes revolvem a lógica do momento, contaminam a realidade com a imaginação. A memória para ele é uma "proliferaçāo anárquica de imagens do passado" (LEVY, p. 107). Incontrolável. Involuntária. Proustiana. Memória do coração - diferente da memória voluntária.

Nunca vivera aquilo. Nunca vira ressurgir assim, sem que quisesse nem calculasse, tantos pedaços de sua vida que ele acreditava esquecidos. (. . . ) Ele não escreve; está fisicamente - e sem dúvida moralmente - incapaz de escrever; mas se escrevesse, se tivesse, não um projeto mas a nostalgia de um último livro e se pudéssemos entrar em sua cabeça para nela decifrar os fiapos de frases que se inscrevem ali, certamente seriam os de um liv ro que ele nunca concebeu; o único livro que ele sempre soube, toda a vida, que nunca escreveria; seria, em 
uma palavra - que adquire neste instante o peso do es sencial - um livro de recordaçöes (LÉVY. p.84-5).

Este é também o projeto do narrador. Este é também o projeto de Lévy. Preencher o silêncio com algo que não sabe o quê. Preencher silêncios impreenchiveis da história com a voz sedutora e enganosa da ficção. Negaçāo do passado ("O passado existe, aliás?", LÉVY, p.88). Negação da "verdade" ("Aliás, esse relato, se ele o escrever, não dirá "a" verdade. Não oferecerá uma versão que, a pretexto de que é sua, invalidará as outras, tachando-as de falsidade", LÉVY, p.87). Negação da ordem e do sentido único (" (. . . ) patéticas tentativas de dar um sentido, apenas um sentido, a uma aventura que não tem nenhum". LÉVY, p.88). Negação do tempo ("Será o primeiro livro (. . . .) que dirá que o tempo de uma vida é o tempo do tempo e que ele obedece a uma lógica bem mais secreta e retorcida", LÉVY, p.89). Antibiografia. Alter-Baudelaire. Baudelaire revisitado.

Por que quis começar por Marcel Proust, julgo que fica claro agora. Queria apontar, lá tão longe, o início da estrada.

No caminho vicinal hoje tomado por Lévy, nāo faltam nem o jogo nem o questionamento das aparências. Não importa o que foi a biografia de Baudelaire. Não importa se é possível ou não preencher seus silêncios. Importa que, como no jogo japonês, os fragmentos acabam por construir "flores, casas, personagens consistentes e reconhecíveis", Bruxelas, a pensão, a Sra. Lepage. os arredores, tudo a sair de uma outra xícara de chá. de um outro jogo. De um outro jogo de fragmentos.

Diz-se com freqüência (e é uma questão polêmica a ser discutida) que nāo há na França hoje um grande romance. Mas como poderia, pergunto, se o que se busca encontrar é a criação modelar de um Proust, de um Gide, de um Malraux, de um Camus? Será possível imitá-los? Será possível igualá-los? Pergunto ainda: será necessário? Ou, na ausência deles, não seria, ao menos, possível relêlos? Relê-los em outras obras, intertextualizá-los em outros textos, puxar fios para outros tecidos? Desfiar as obras e desafiar os tempos? Talvez os tempos pós-modemos exijam outros romances. Que escreveriam, hoje, Gide e Proust? Camus e Malraux?

$O$ que hoje escreveriam, é certo que nāo o sabemos. O que sabemos, de œrto, é que sem eles nāo é possível escrever. Seja para resgatar a dignidade da condição humana, seja para questionar o absurdo da morte, seja para discutir o conteúdo do romance, seja para 
recuperar o tempo perdido no texto de memórias, nāo é possível escrever sem eles.

Não caberia então buscar, no romance atual, o eco construtor de vozes tão presentes? Mergulhar no jogo da memória das obras que se recuperam em outras obras?

No tão conhecido capítulo de Les faux-monnayeurs de André GIDE, em que Édouard expōe suas idéias sobre o romance, o personagem refere-se a um "camet", um bloco de notas, um diário em que anota, nāo o romance que está escrevendo, mas as dificuldades que encontra:

(. . . ) esse caderno [diz ele] contém a crítica de meu romance; ou melhor: do romance em geral. Pensem no interesse que teria para nos um cademo semelhante com notas de Dickens ou de Balzac; se tivéssemos o diário da Educaşão sentimental, ou dos Irmāos Karamazov! a história da obra, de sua gestaçāo! (GIDE, p. 186).

Se a história reconhecer que a literatura francesa contemporânea teve um carater inovador e lhe conceder lugar no "museu imaginário" da literatura (coisa em que acredito), então suas obras serão vistas como herdeiras de grande linhagem e críticos hão de estudar sua gestaçāo; se a posteridade, entretanto, provar que o romance contemporâneo não é digno de menção ou não tem o porte da obra dos grandes mestres, talvez se lhes possa, ao menos, reconhecer o mérito de diários onde se assentaram as dificuldades da escritura, traçando com eles, senão a história de cada obra, pelo menos a gestação do que poderia ser a história do romance francês do século XX.

Quis começar por Marcel Proust. À luz do jogo, tentei identificar os fragmentos da escritura de Bernard-Henri Lévy. Quero terminar por André Gide.

No Tratado do Narciso, o Narciso de GIDE transforma o mito grego: nāo se vê, sua imagem se confunde com o que vê; quando consegue ver-se, tenta agarrar a própria imagem que, no movimento das águas, se estilhaça. $\mathrm{Na}$ imagem do Narciso estilhaçado, não se contempla a cópia, mas as possibilidades da cópia, não se contempla o mesmo, mas as diferenças, a alteridade. São essas diferenças que se disseminam. Biografia, antiobiografia, alter-biografia. Leitura às avessas/Narciso estilhaçado. 

Gide

Quis começar por Marcel Proust. Quero terminar por André

\section{RESUMO}

Reflexão sobre a narrativa francesa do século $X X$, através do romance Os últimos dias de Charles Baudelaire, de BernardHenri LÉVY. Aspectos pós-modernos. A leirura às avessas. Memória e fragmentos. $O$ jogo da escritura reinventando a biografia. Alter-biografia.

\section{REFERÊNCIAS BIBLIOGRÁFICAS}

1 GIDE, André. Les faux-monnayeurs. Paris : Gallimard, 1925.

2 LÉVY, Bernard-Henri. Os últimos dias de Charles Baudelaire. Rio de Janeiro: Rocco, 1989.

3 PROUST, Marcel. Du côté de chez Swann. Paris: Gallimard, 1954.

4 Le temps retrouvé. Paris: Gallimard. 1954. 